\title{
So We May Not Forget!
}

\author{
Ami E. Iskandrian, MD, MACC, MASNC ${ }^{a}$ \\ a Division of Cardiovascular Diseases, Department of Medicine, University of Alabama \\ at Birmingham, Birmingham, AL, England
}

Received May 23, 2016; accepted May 23, 2016

doi: 10.1007/s12350-016-0559-3

"We are what we repeatedly do. Excellence, then, is not an act, but a habit." Aristotle (384 вC-322 вC).

"Those who cannot remember the past are condemned to repeat it"' (Santayana, 1863-1952).

Today's buzz words in imaging circles are the newest developments in echocardiography (ECHO), cardiac magnetic resonance imaging (cMR), computed tomography (CT), and nuclear cardiology (NC). The journals (JNC included) and local and national meetings are active in portraying advantages of one imaging method over the others and more recently the advantages of combining more than one (hybrid imaging). I, like many of you, enjoy the various viewpoints which are often emotionally charged, but that is not the theme of this Editor's Page. Rather, I'd like to reflect on the period of time when modern cardiac imaging got its start and when NC was the only show in town.

What happened during the 1970s? Was the field alive or hibernating? What were the debates about? What was important? How did NC survive (and thrive)? The answers to these and many more questions are important today because some of the giants of this era have either passed away or have retired. We need to keep the memory alive, so that we can learn from past and this piece is just a starting point. I invite all those with stories to tell to share them with our readers under the banner "so we may not forget", to remind the younger generation of the trials and tribulations. My generation is lucky to have witnessed the changes from the start and therefore are in a position to reflect and share the history in the making.

A group of about 500 individuals later referred to as the "founding fathers" saw the need for a society, and

Reprint requests: Ami E. Iskandrian, MD, MACC, MASNC, Distinguished Professor of Medicine and Radiology, Division, Cardiovascular Diseases, Department of Medicine, University of Alabama at Birmingham, 318 LHRB/ 1900 University BLVD, Birmingham, AL 35294; aiskand@uab.edu

J Nucl Cardiol 2016;23:643-4.

$1071-3581 / \$ 34.00$

Copyright (C) 2016 American Society of Nuclear Cardiology. in 1993 ASNC was formed. A year later in 1994, JNC was founded, and two years after that, the CBNC (Certification Board of Nuclear Cardiology) was formed. During those early years, there were countless scientific meetings everywhere sponsored by ACC, AHA, Society of Nuclear Medicine, American Society of Radiology, and then by ASNC. The meetings were held in the old Heart House, local chapters, free-standing courses in medical centers, grand-rounds, and retreats across the USA and then globally.

All of these gatherings were very well attended, despite the many required registration fees! The "read with experts" sessions were particularly popular (as they are now). The national meetings often had standing room only in the oral presentation sessions. The retreats brought together people from all walks of life who had a genuine interest in promoting the field; the focus was the field and not the individual. In my mind, that was the factor that promoted the unprecedented growth during those years. (At one time, the waiting period was $>1$ year for a stress nuclear study in my lab in Philadelphia!) The emphasis was to train, educate, and improve the quality from coast to coast. There was so much to learn and so much to teach and very few "superstars," so the demand was great.

What were the debates about? A few of the items that were debated emotionally and with frequency pertained to perfusion imaging (Table 1). There are other debate examples related to radionuclide angiography (RNA) [Parenthetically, early on, rest/exercise RNA was used as frequently as perfusion imaging after the lead article in NEJM by Borer et al in 1977 on the diagnostic value of exercise RNA] (Table 2).

There was a great enthusiasm for developing new methods, protocols, stress agents, tracers, and hardware. Many are in use now, but some did not survive! Here is a sample of those who failed the test of time; Technetium99m teboroxime, Technetium-99m Noet, I-123-BMIPP (beta-methyl-iodophenylpentadecanoic acid), !-123IPPA (iodophenylpentadecanoic acid), VEST nuclear probe (Nuclear Holter), Tc-99m pyrophosphate for 
Table 1. Topics of debates in the early history of cardiac nuclear imaging related to perfusion

\begin{tabular}{|c|c|}
\hline 1. & What are the tracer kinetics? \\
\hline 2. & When to image after thallium injection? \\
\hline 3. & What is Creep? \\
\hline 4. & $\begin{array}{l}\text { When acquiring planar perfusion imaging, Should the } 3 \text { views be anterior, } 30 \text { LAO } \\
\text { and } 45 \text { degree LAO or anterior, } 45 \text { degree LAO and lateral? }\end{array}$ \\
\hline 5. & $\begin{array}{l}\text { Should the lateral projection be done by moving the camera head (single head) or } \\
\text { by moving the patient on his/her side? }\end{array}$ \\
\hline 6. & Should images be acquired for a pre-set counts or a pre-set time? \\
\hline 7. & Should the images be interpreted qualitatively or quantitatively? \\
\hline 8. & Should a lead shield be used to decrease sub-diaphragmatic activity? \\
\hline 9. & $\begin{array}{l}\text { What is the best way to measure } \mathrm{L} / \mathrm{H} \text { ratio: mean counts over the entire cardiac ROI } \\
\text { or maximum counts over the most normal area? }\end{array}$ \\
\hline 10. & Is SPECT better than planar imaging? \\
\hline 11. & Is 2-head camera system preferred over 3-head camera system? \\
\hline 12. & Is step- and -shoot acquisition better than continuous acquisition? \\
\hline 13. & Is technetium-99 m MIBI better than thallium? \\
\hline 14. & Is technetium-99 m tetrofosmin better than thallium or MIBI? \\
\hline 15. & Is re-injection thallium necessary? \\
\hline 16. & $\begin{array}{l}\text { Are } 3 \text { or } 2 \text { sets of images needed: stress thallium/delayed thallium/reinjection vs. } \\
\text { stress thallium /reinjection (skip the delayed!)? }\end{array}$ \\
\hline 17. & $\begin{array}{l}\text { Can thallium images be gated? Which one-day imaging protocol is preferred: rest/ } \\
\text { stress or rest/stress? }\end{array}$ \\
\hline
\end{tabular}

Table 2. Topics of debates in the early history of cardiac nuclear imaging related to RNA

\begin{tabular}{ll}
\hline 1. & Which method is better for LVEF measurement: MUGA or first-pass? \\
2. & Can first- pass RNA be done using Anger camera (vs. dedicated mutli-crystal \\
gamma camera)? \\
3. \\
What is the best method to measure RV-EF? \\
6. & What is the best method to measure LV volumes? \\
7. & What is the best method to measure intra-cardiac shunts? \\
8. & Could valvular regurgitation be quantified? \\
9. & What is the best method for regional function assessment: Wall motion or phase \\
10. & What is the best method to label RBC's for MUGA study?
\end{tabular}

infarct avid imaging, myocarditis and cardiac contusions (now used for wild type-transthyretin cardiac amyloidosis), Technetium-99m-labeled Annexin-V for acute MI and apoptosis (though still available for research use), AMISCAN, Arbutamine, Binodenoson, and Apadenoson.

Of interest, Tc-99m teboroxime was approved by FDA but later withdrawn. It had higher extraction fraction than any of the current SPECT tracers, and its only fault was that it washed out rapidly from the myocardium. It is tempting to speculate the fate of this tracer if introduced in our current era, where fast imaging is feasible with the newer generation of imaging systems!

These issues are as important today as they were back then, but they have lost the glamour and widespread interest and sadly some of the people who pioneered them. To be on the cutting edge, we need to move forward, but the Journal is also committed to keeping the path to excellence well-rooted in the past. 